\title{
Correction to: Characteristics of topographic submesoscale eddies off the Crimea coast from high-resolution satellite optical measurements
}

Anna Aleskerova $^{1} \cdot$ Arseny Kubryakov $^{1} \cdot$ Sergey Stanichny $^{1} \cdot$ Alessia Medvedeva $^{1} \cdot$ Evgeniy Plotnikov $^{1}$. Artem Mizyuk $^{1} \cdot$ Liudmila Verzhevskaia $^{1}$

Published online: 11 May 2021

(C) Springer-Verlag GmbH Germany, part of Springer Nature 2021

Correction to: Ocean Dynamics https://doi.org/10.1007/s10236-021-01458-9

The original version of this article unfortunately contained a mistake. The presentation of Figs. 4, 5, 6, 7, 8, 9 and 10 were incorrect. The corrected figures are given below.

The original article has been corrected.

The online version of the original article can be found at https://doi.org/ 10.1007/s10236-021-01458-9

Arseny Kubryakov

arskubr@mhi-ras.ru

Federal State Budget Scientific Institution "Marine Hydrophysical Institute of RAS", Sevastopol, Russian Federation 

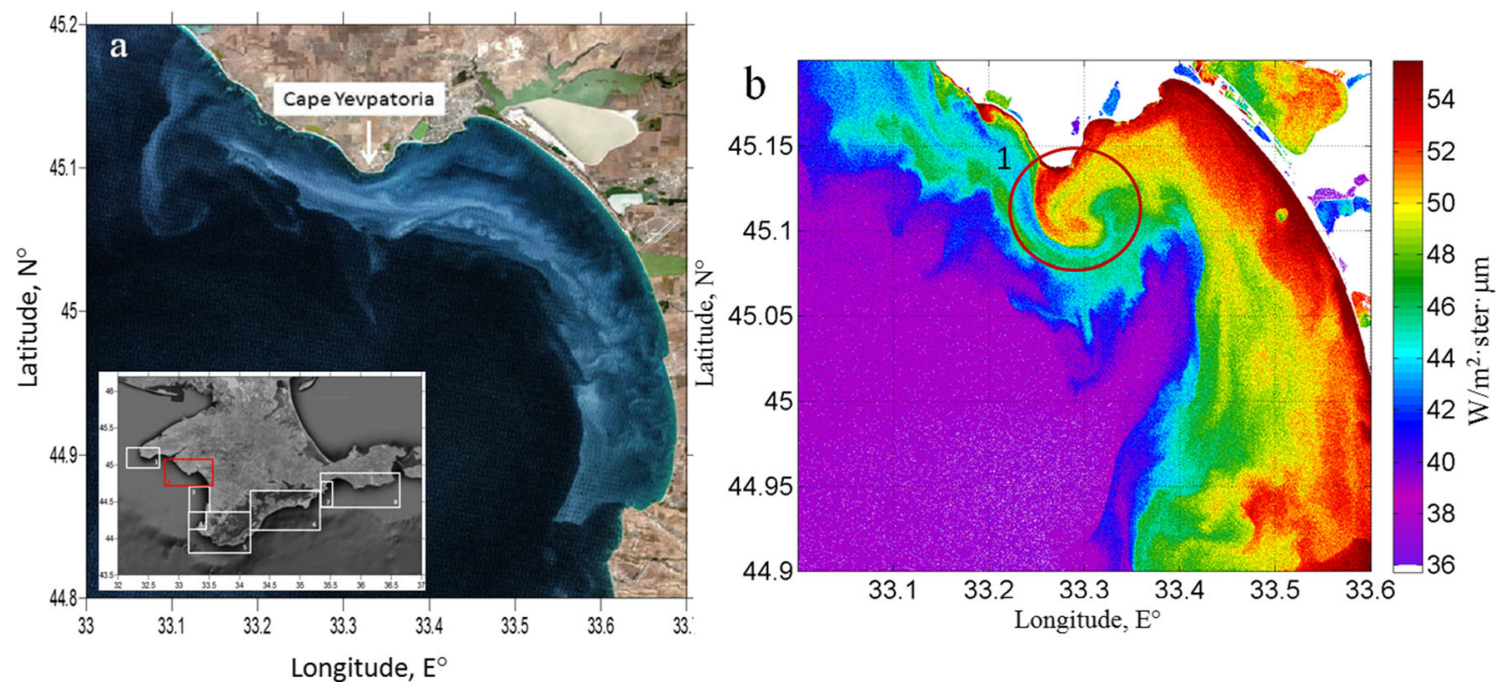

Fig. 4 Mushroom-like submesoscale structure near Cape Yevpatoriiski in a Landsat-5 RGB image dated 23 September 2009. b Landsat-7 radiance at $\lambda=443 \mathrm{~nm}$ on 14 March 2000

Fig. 5 a SCE formation on the periphery of large AE: General view - TSM data from MODIS on 8 September 2017, zoomed in area near cape Lukull - RGB composition from Sentinel-2 dated 9 September 2017 showing two SCE. b Mushroom-like structures in Landsat-5 radiance at $\lambda=475 \mathrm{~nm}$ on 25 August 2010. c SCE formation on the periphery of large AE near the cape Lukull in Sentinel-2 RGB image dated 29 October 2017. d Landsat-5 radiance at $\lambda=475 \mathrm{~nm}$ showing a number of submesoscale structures formed near the mouth of small rivers on 1 August 1984
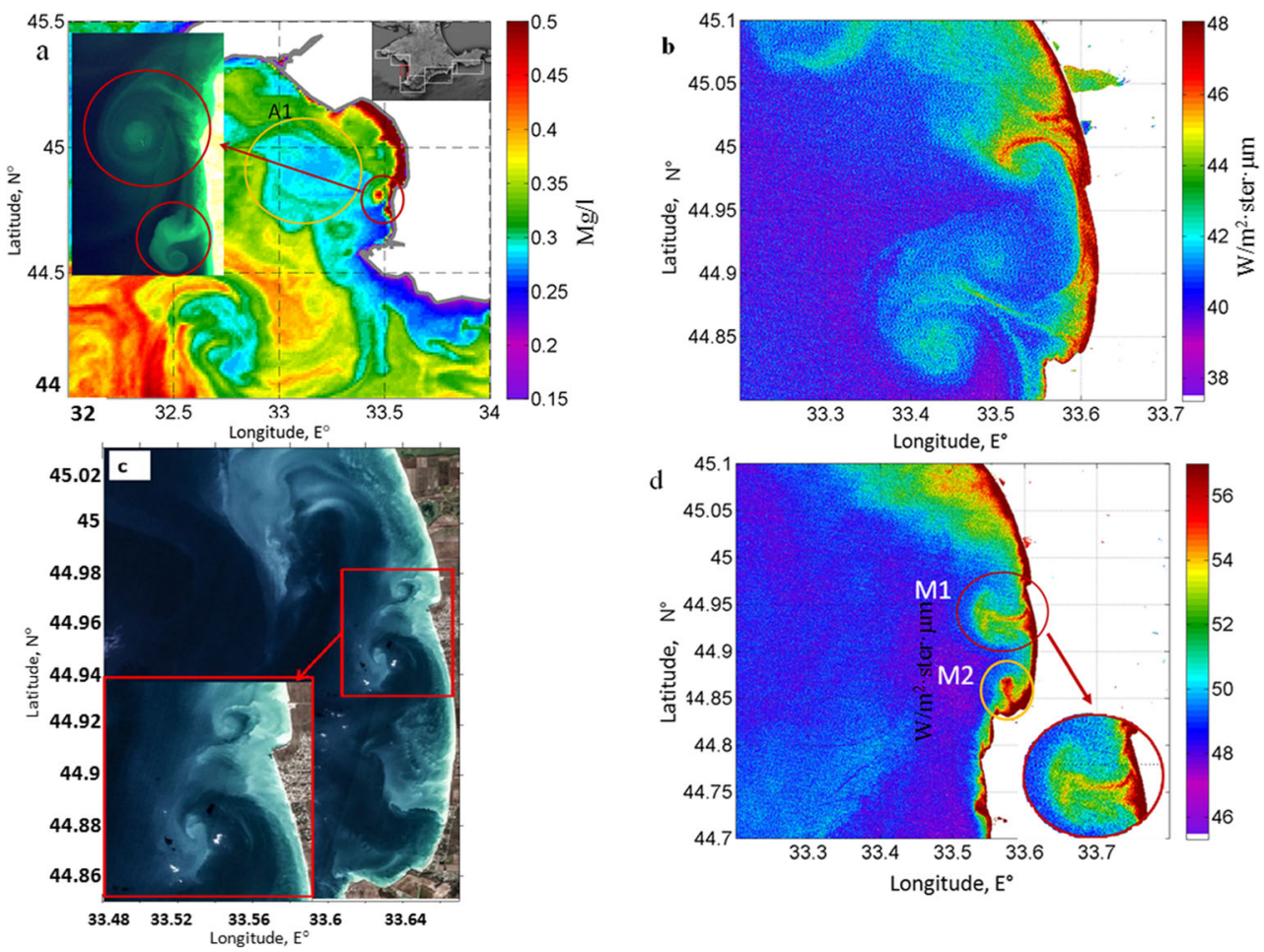

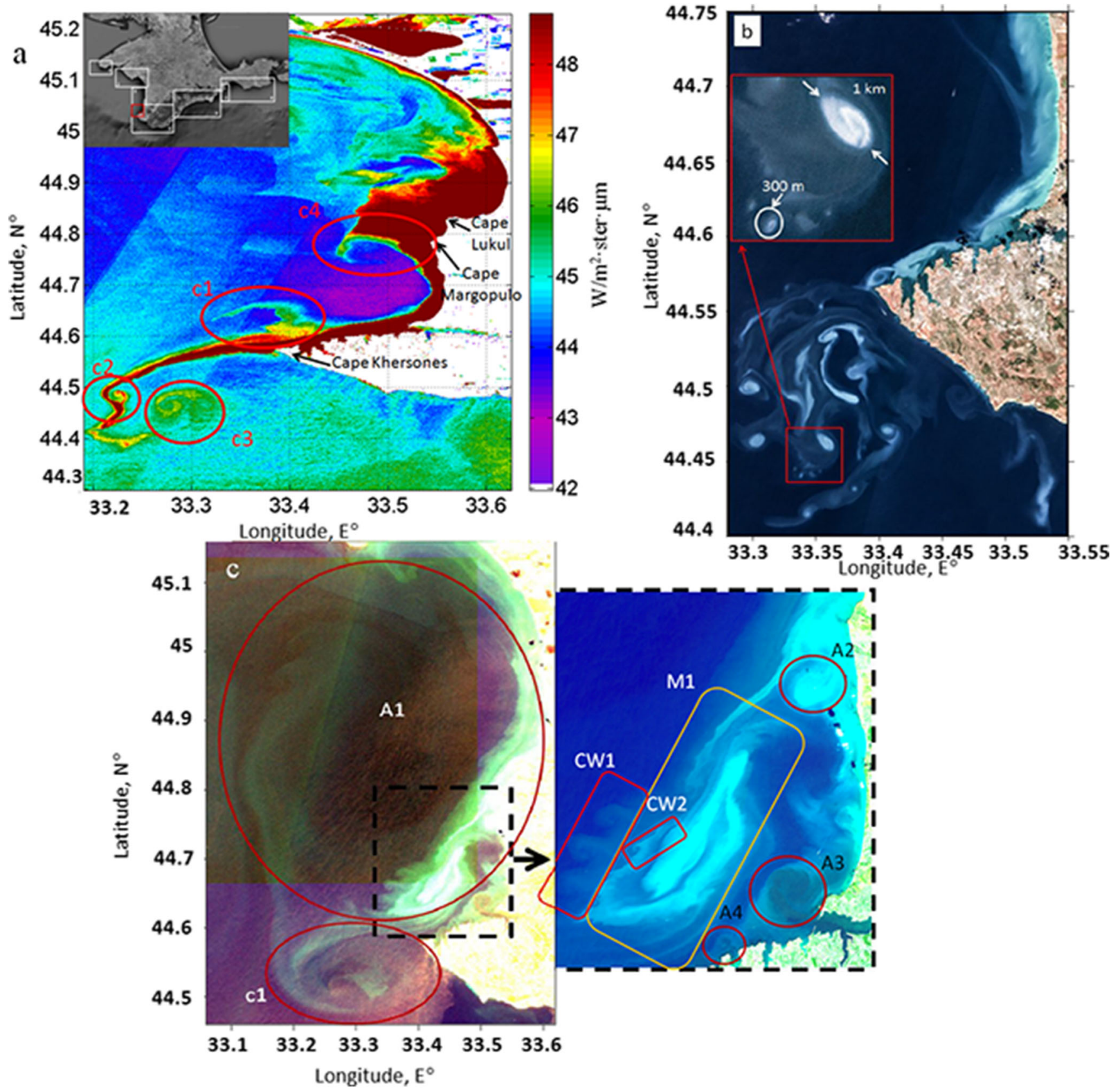

Fig. 6 a Formation of a series of SCE on the periphery of southward jet near the cape Hersones in Landsat- 8 radiance at $\lambda=475 \mathrm{~nm}$ on 20 October 2013. b Densely packed group of small SCE to the south of the cape Hersones in Sentinel-2 RGB image dated 24 September 2017. c Complex

submesoscale structure near the Western Crimea coast on Sentinel-2 RGB image dated 25 August 2017 (the whole west coast of the Crimea — left, and a zoomed part — right) 

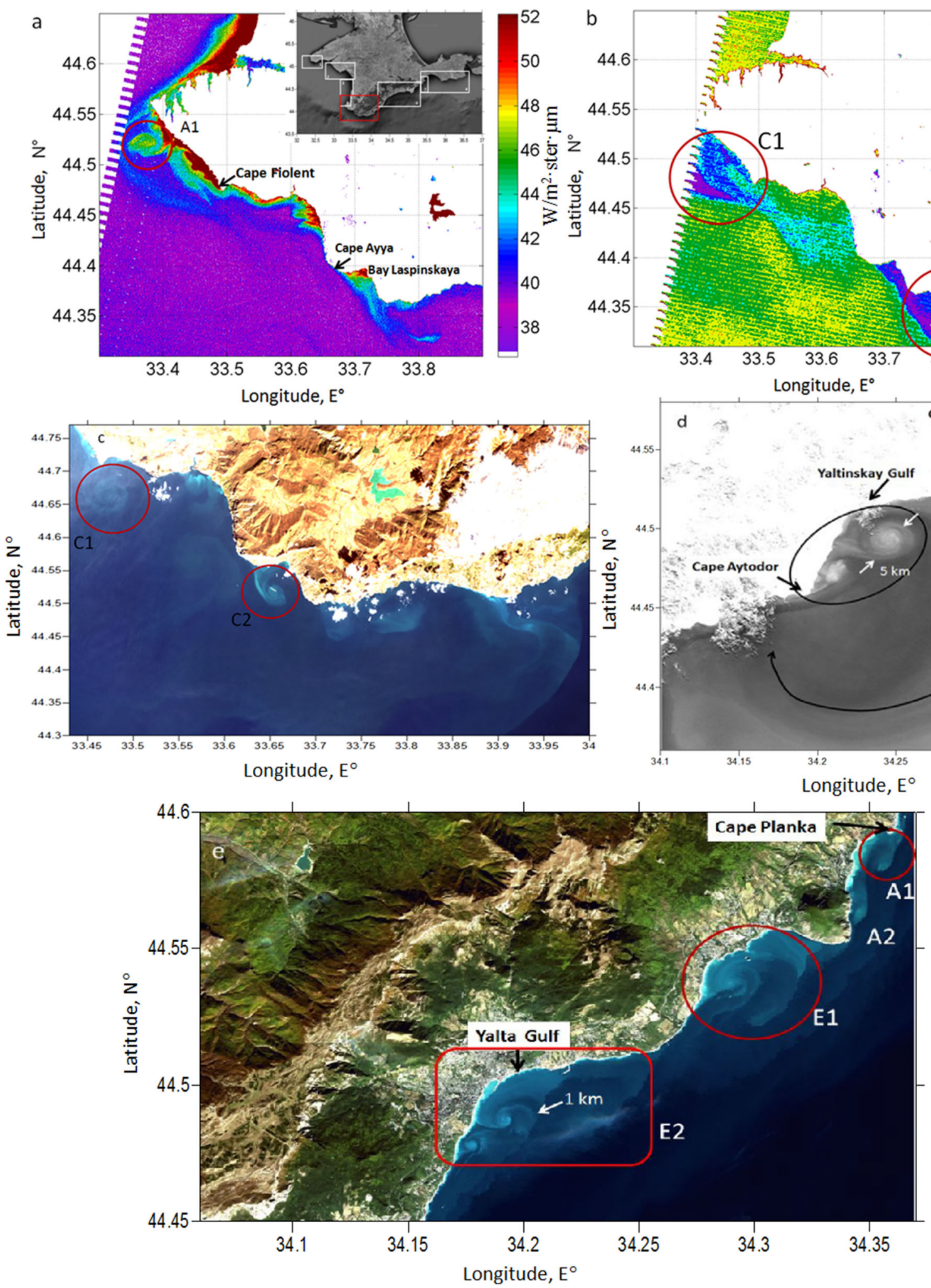

Fig. 7 a, b Cyclonic filaments on the upwelling periphery on Landsat-5 image on 3 September 2010 in optical (a) and infrared (b) channels. c Series of SCE near the South Crimea coast seen in Landsat-8 RGB image on 26 February 2017. (d) The formation of the chain of SCE on the periphery of larger AE in Sentinel-2 optical image on 6 July 2017. e Formation of SE in the bays of South Crimea in Sentinel-2 RGB image on 19 October 2016 

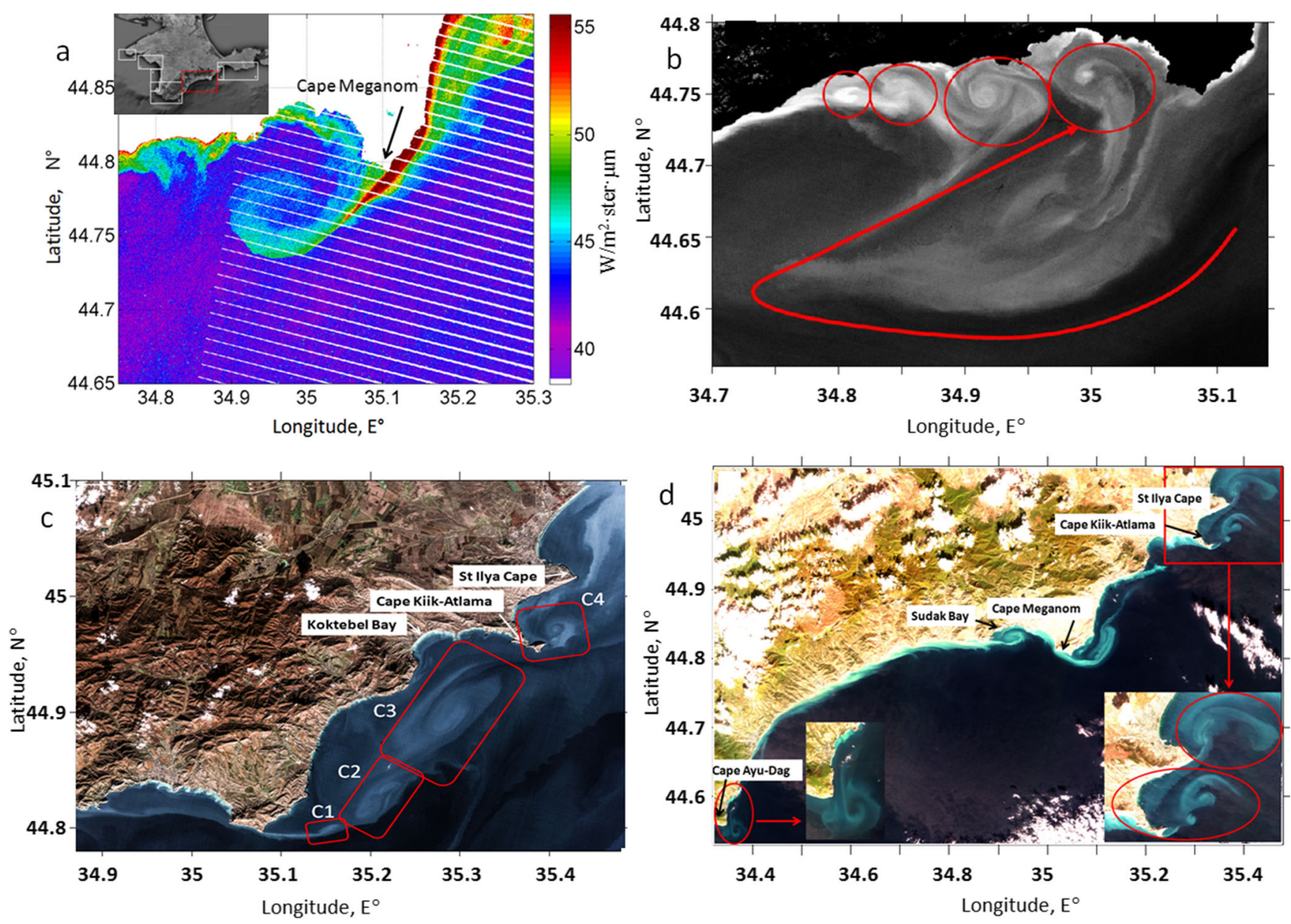

Fig. 8 a Formation of a submesoscale anticyclone behind Cape Meganom in Landsat-7 radiance at $\lambda=475 \mathrm{~nm}$ on 11 September 2010. b Chain of SCE on the periphery of coastal SAE in Landsat-8 image on 21

August 2017. c Chain of SCE formed behind Cape Meganomin Sentinel2 optical image on 8 December 2017. d Several SCEs formed behind the capes of the South Crimea in optical Sentinel-2 image on 9 October 2016 

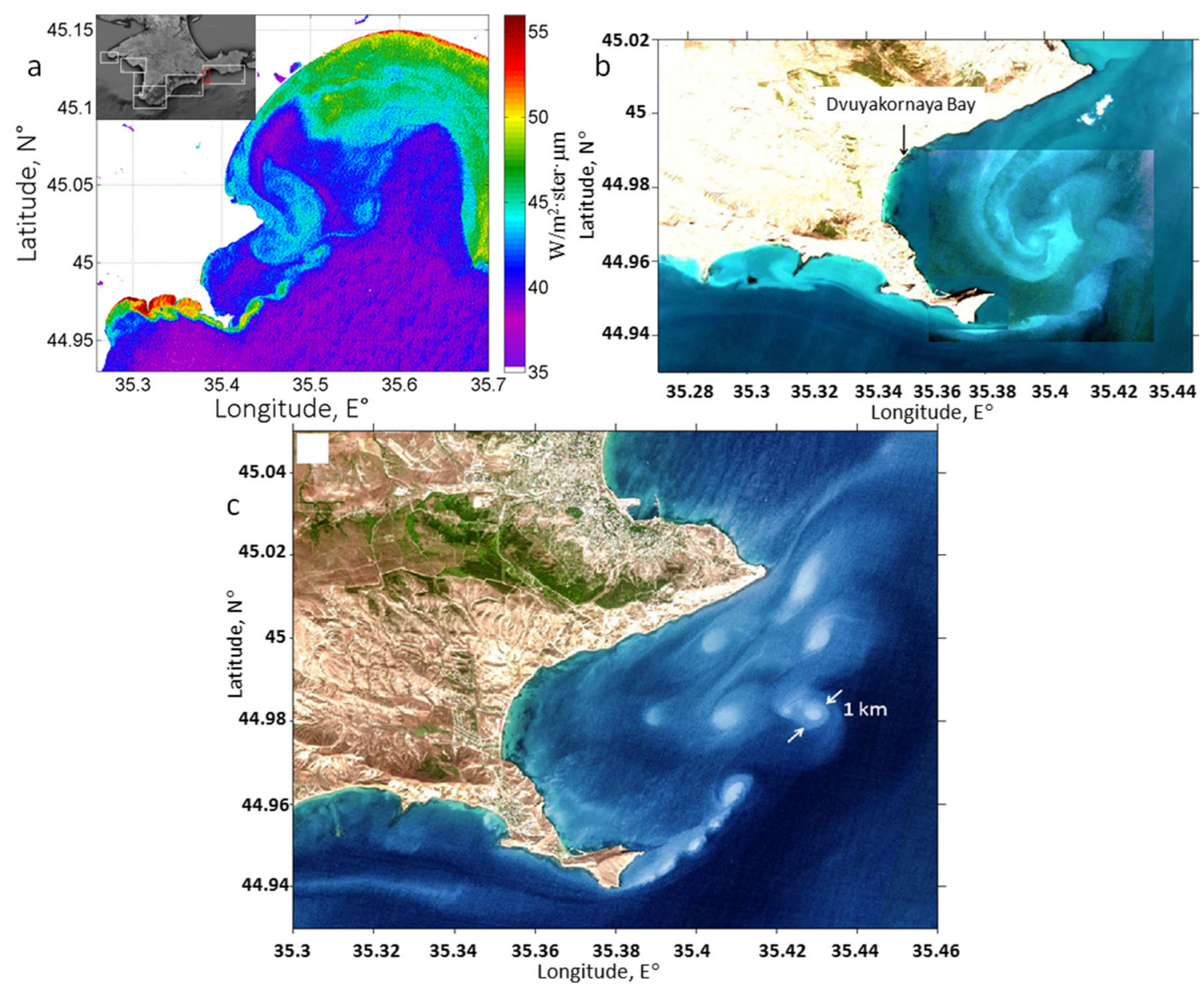

Fig. 9 Formation of a series of SCE behind the cape Kiik-Atlama. a Landsat- 5 radiance at $\lambda=475 \mathrm{~nm}$ on 3 September 2010. b Sentinel- 2 RGB image on 26 February 2017. c Sentinel-2 RGB image on 2 September 2015 


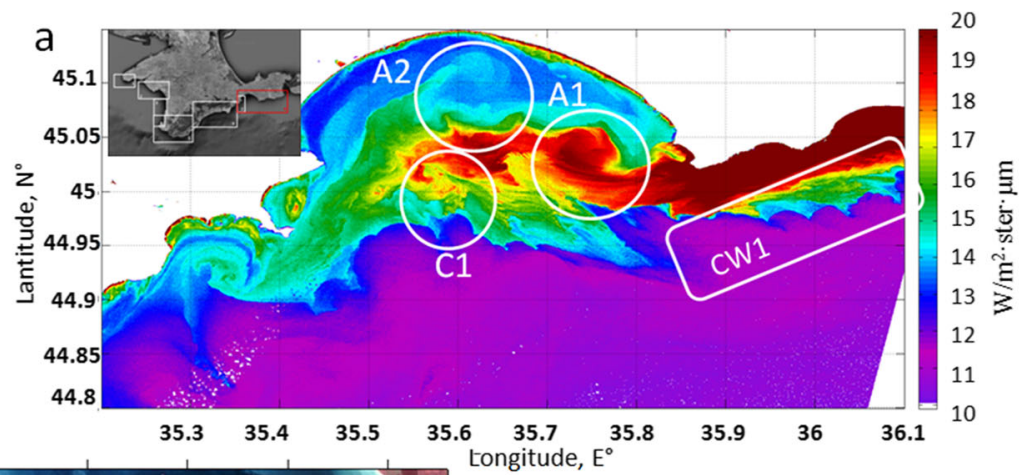

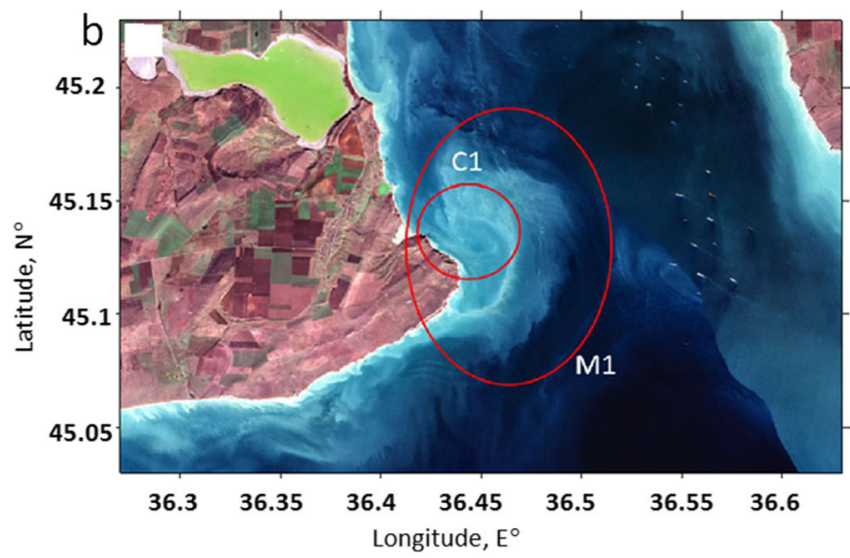

Fig. 10 a Complex submesoscale structures formed due to interaction of the jet of Azov water with the Feodosiya Bay on Landsat- 8 radiance at $\lambda=550 \mathrm{~nm}$ dated 22 November 2016. b Formation of the mushroom

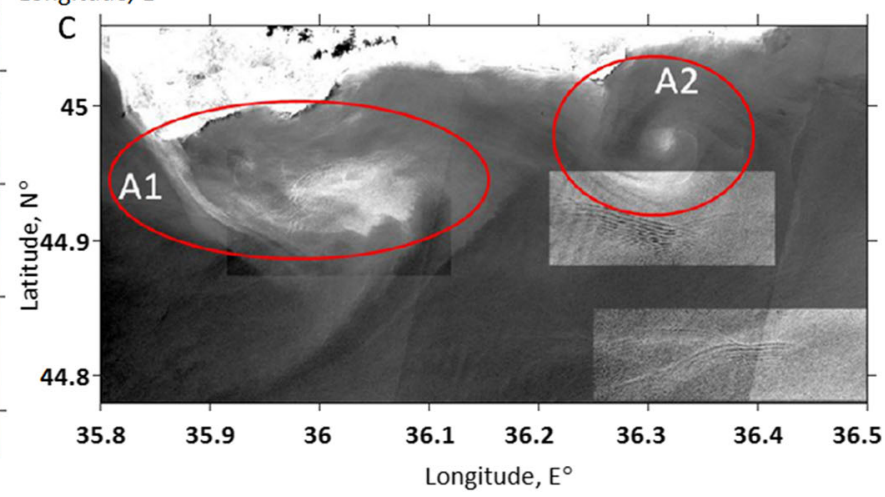

current near cape Takil in Sentinel-2 image on 30 January 2016. c Formation of SCE behind cape Chauda and Opuk in Sentinel-2 RGB image on 3 July 2018 